\title{
Analyzing Human Error in Municipal Water Systems Using Systematic Human Error Reduction and Prediction Approach SHERPA Method
}

\author{
Behzad Fouladi Dehaghi, ${ }^{1}$ Ali Rastin, ${ }^{1}$ Maryam Malekzadeh, ${ }^{1}$ and Leila Ibrarahimi Ghavamabadi ${ }^{2,}$ \\ ${ }^{1}$ Department of Occupational Health, Health Faculty, Ahvaz Jundishapur University of Medical Sciences, Ahvaz, IR Iran \\ ${ }^{2}$ Department of Environmental management-HSE, Islamic Azad University, Ahvaz Branch, Ahvaz, IR Iran \\ "Corresponding author: Leila Ibrarahimi Ghavamabadi, Department of Environmental management-HSE, Islamic Azad University, Ahvaz Branch, Ahvaz, IR Iran. Tel/Fax: \\ +98-61337385318, E-mail: ebrahimi.ghavam@gmail.com
}

Received 2016 November 12; Revised 2017 January 14; Accepted 2017 January 18.

\begin{abstract}
Background: The perception that water treatment and supply systems are not safe against accident and human errors as well as disease outbreaks is growing. Many major events around the world have been attributed to human error. In general, human errors are defined as situations where planned series of mental or physical activities fail to achieve its desired result.

Methods: This cross-sectional study was performed to predict human error in the Khorramabad water treatment plant. Human error in the telemetry control room as well as relevant units was assessed with standard charts, tables, and reference work sheets. At first, all different activities of the unit were considered after interviewing the workers as well as consulting with supervisors and also by hierarchical task analysis HTA. Then the SHERPA method was applied to identify potential human errors.

Results: Seventy-nine human errors were identified in various job tasks. Results showed that $51.8 \%$ of them are action errors, $38.4 \%$ are checking errors, $7.59 \%$ are retrieval errors, $0.006 \%$ is communication errors, and $0 \%$ for selection errors.

Conclusions: It can therefore be concluded that the most prevalent errors are checking and action errors. Thus, it is suggested that work instructions, staff training, and employing inspection operators to monitor the performances should be considered as a priority. Furthermore, it can be concluded that SHERPA is appropriate for many industries such as water treatment plants.
\end{abstract}

Keywords: Human Error, SHERPA, Water Treatment Plant

\section{Background}

The importance of the human element in complex socio-technical systems in the study and application of risk and safety management is growing (1). In recent decades, human error element in accidents and organizational assignment has been growing continuously, which can be explained by 2 aspects of technological reasons: 1 . the complexity of the system and often poorly defined role of human operators in the control loop and 2. increase the reliability of mechanical parts, electrical, and information processing system (2). Contemporary thinking on human factors and related fields as a result, rather than a cause, of the failure of the system is characterized by human error (2). In this way, many industries are now required to integrate human factors research and risk management principles to detect the failure. Risks due to human element in water treatment and delivery systems have received little attention in the academic literature. Given the potentially serious nature of the accidents related to water treatment and distribution infrastructure, including threats to public health and large-scale destruction of property, it will have to play more of an active role in understanding and managing risks from human element (2). In water supply systems that are responsible for the preparation of drinking water, problem diagnosis is in the earliest stage (3). Given the potentially great nature of the accidents related to water treatment and distribution substructure, including threats to public health and large-scale demolition of property, it will have to play a more active role in conception and managing human risks (2). This knowledge is growing between the different stakeholders that water supply systems, even in developed countries, can not immune outbreaks of large-scale pollution. The case of E. coli contamination in Walkerton, Ontario is a well-known example in this subject (4). Other events due to human error in water supply and distribution systems can be mentioned such as this event that, in early 2009, occurred in the water treatment plant in Queensland, in which evaluation reports highlighted the cause of this incident as human error (2). Human errors contribute to the majority of incidents within complex systems (5). Extensive research that has been done in the field of industrial accidents, show that human fault is a main contributor to the reliability and risk of many systems (6): over 90\% in nuclear process (7), over $80 \%$ in chemical industries (8), over $75 \%$ of marine losses (9), and over $70 \%$ of aviation events $(10,11)$. A large number of accidents resulting in many in- 
juries have occurred due to human errors $(5,6,12)$. In general, human errors are defined as those situations where planned series of physical or mental activities fail to gain its intended result (13). According to Stanton et al. human errors can be predicted using the analysis of individual activities and reviewing of things that can lead to errors (14). Therefore, human errors are predictable and can be evaluated by performing research. They also argued that error prediction techniques are an important tool in humancentered design approaches. Since human error is not considered as accidental events, they should be identified and classified with tools such as taxonomies (14), which involve using structured methods for predicting errors created by human operator during task performance (15). Embrey introduced this systematic human - error reduction and prediction approach (SHERPA) in 1986. The SHERPA is one of the most enforceable methods for studying human errors (16). This technique is used to predict human error, to identify and assess methods for reducing the errors based on the behaviors as was used in hazardous materials transport, gas and oil exploration, cockpit, and ticket vending machine to determine human errors $(15,17)$. Many studies have shown that SHERPA also has acceptable test/retest reliability (18-20). Since water supply and distribution system are among the critical industries in our country, the consequences resulting from human error will be economically, socially, and environmentally unpleasant. Supply and distribution system of Lorestan water treatment plant for assessing operators' errors selected to be assessed by this method in this study.

\section{Objectives}

The aim of this study was to recognize operators' errors in water supply and distribution system of Lorestan water treatment plant in order to take effective actions towards reduction of human errors.

\section{Methods}

This study was a cross-sectional study, which aims at predicting human errors by using SHERPA technique at water supply and distribution system in Lorestan water treatment plant in 2015. The participating group included operators who worked in the control room of water treatment plant, and were particularly responsible for equipment control and orders throughout monitors and indicators. In this section, 14 operators who worked in 3 shifts in circulation were studied. Data was collected through conducting observations and interviews with 14 operators over a period of 2 months. In this study, the types of errors and different consequence of their occurrence based on the structure of the SHERPA method were identified by the researcher in the worksheets, according to the following steps (21): in the first stage hierarchical task analysis (HTA), an analysis with the use of HTA to break the overall work tasks functions to individual details, and introducing potential performance of the work program, which shows the sequence $(22,23)$ (Figure 1 ). By the disintegration of job into divided tasks, the analysis jobs towards a failure mode effects analysis by adjudging that each task can be considered in terms of classes of error modes. Task classification, as the second stage, involves categorizing each task operation into one of the following classifications (information communication, selection, action, retrieval, checking), by using a checklist that is shown in Table 1. Furthermore, Table 2 showed the error code was determined and recorded in the error mode column of the table. These arrangements then allow the analyst to consider likely errors associated with that operation. (Stage 3: HEI). Error identification: After the classification of tasks into behavior types, human error of each task made by the operator will be identified by the analyst according to the error taxonomy (24). Hence, the analyst explains the consequences (Stage 4: consequence analysis) and the recovery potential (Stage 5: recovery analysis) associated with each error. Ordinal probability analysis (Stage 6) using information gained from tentative data and/or input from an expert. Criticality analysis (Stage 7) requires the analyst to attend if the outcomes associated with an error were critical. In steps 6,7 hazard analysis was done according to the risk assessment matrix (25), presented in Table 3. Remedy analysis as a last stage, the analyst uses a structured brainstorming training to develop ways of omitting or reducing the effects of the error (19).

\section{Results}

In this study, the HTA table has been designed and SHERPA worksheets were also completed for the operator's 5 major tasks. The results of the SHERPA technique application for these tasks showed that in 34 sub-tasks derived by HTA technique, a total of 79 errors were detected in the operator's tasks. The total number of errors identified in 5 groups of errors is described in Table 4. Regarding the percentage of the error rate shown in Figure 2, action errors with $51.8 \%$ and frequency of 41 forms the largest number of errors, furthermore, checking errors with $38.4 \%$ and retrieval errors with $7.5 \%$, communication errors with $0.006 \%$ were respectively the most recorded errors. The least amount of error is selecting error. The probabilities of error for the total errors were determined, so that $12.8 \%$ of them were errors with high event, $41 \%$ medium, and $46.1 \%$ low event. The operators' risk of errors and their level of 


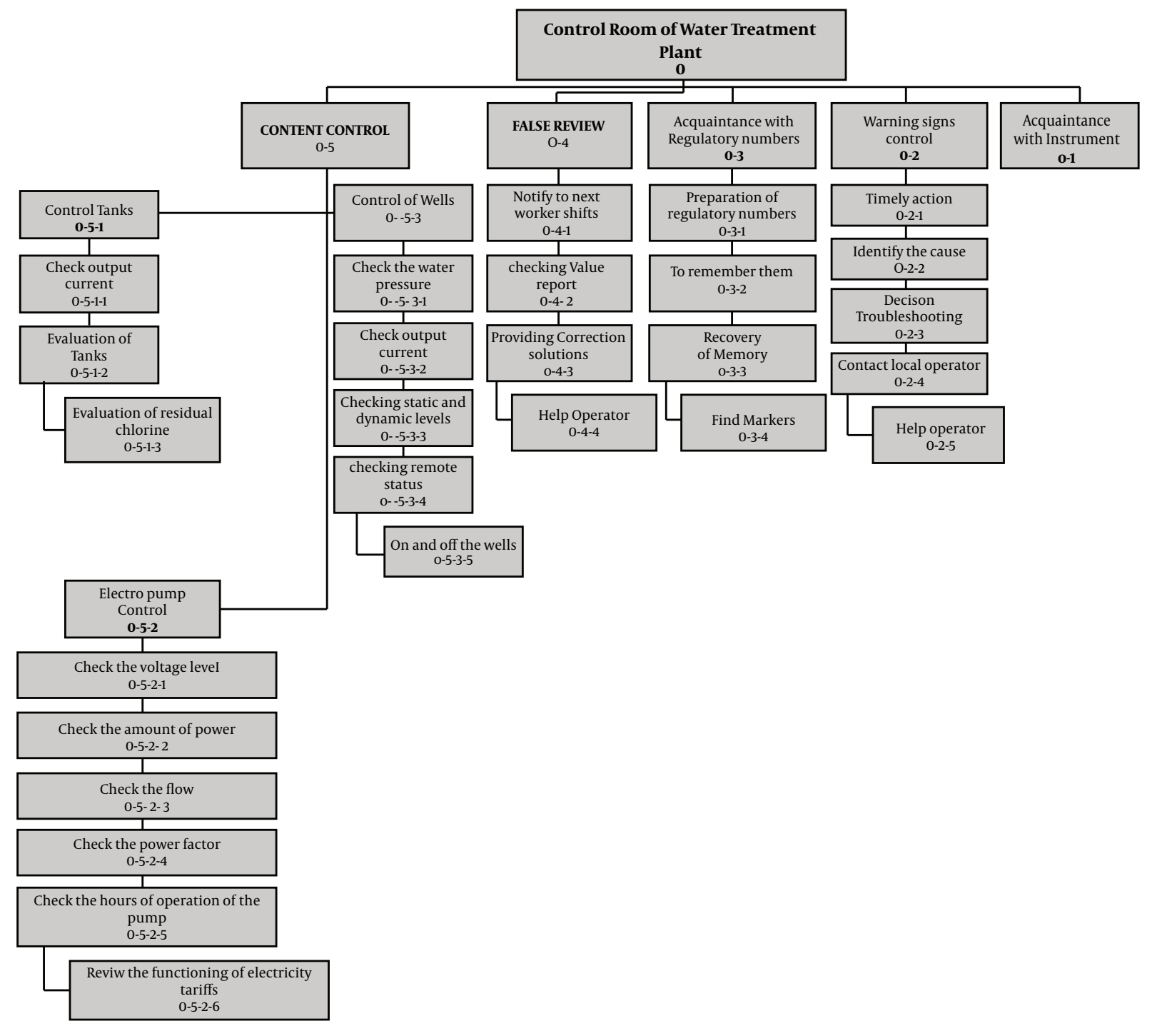

Figure 1. Hierarchical Task Analysis in the Control Room Water Treatment

errors were determined in Table 5, regarding the risk of errors, 4 errors (10.5\%) were in an unacceptable level of risk, 28 errors (73\%) in undesirable risk level, 4 errors (67.1\%) in acceptable level with reviews, and 2 errors (5\%) in acceptable level risk, with no need to review. Risk level of errors separately for each type of tasks is presented in Table 5. After-reforming risk level typically changed; therefore unacceptable, undesirable levels of risk are decreased ( 0 , $10.5 \%)$. Figure 3 shows the proposed correction action to reduce each of the errors.

\section{Discussion}

The main objective of this study was to identify water supply and distribution system control room operator errors during process control, and to determine the level of risk of these errors and also to determine the risk level after the corrective action is proposed for each situation. Evaluation of human errors using SHERPA technique shows that, action errors are the most frequent in the operator's tasks with $51.8 \%$, checking errors were the second most important errors, while selection errors were the least important ones. Regarding action errors, as also shown in the results, operation too long/short, operation incomplete showed most of the action errors in this study. These types of er- 
Table 1. SHERP an Error Mode Checklist

\begin{tabular}{|c|c|c|}
\hline Error Category & Error Code & Error Mode \\
\hline \multirow{10}{*}{ Action Error } & A1 & Operation too long/short \\
\hline & A2 & Operation mistimed \\
\hline & A3 & Operation in wrong direction \\
\hline & A4 & Too little/much operation \\
\hline & A5 & Misalignment \\
\hline & A6 & Right operation on wrong object \\
\hline & A7 & Wrong operation on right object \\
\hline & A8 & Operation omitted \\
\hline & A9 & Operation incomplete \\
\hline & A10 & Wrong operation on wrong object \\
\hline \multirow{6}{*}{ Checking error } & $\mathrm{C} 1$ & Check omitted \\
\hline & $\mathrm{C} 2$ & Check incomplete \\
\hline & $\mathrm{C} 3$ & Right check on wrong object \\
\hline & $\mathrm{C} 4$ & Wrong check on right object \\
\hline & $\mathrm{C}_{5}$ & Check mistimed \\
\hline & C6 & Wrong check on wrong object \\
\hline \multirow{3}{*}{ Retrieval error } & R1 & Information not obtained \\
\hline & R2 & Wrong information obtained \\
\hline & R3 & Information retrieval incomplete \\
\hline \multirow{3}{*}{ Communication error } & I1 & Information not communicated \\
\hline & I2 & Wrong information communicated \\
\hline & I3 & Information communication incomplete \\
\hline \multirow{2}{*}{ Selection error } & S1 & Selection omitted \\
\hline & S2 & Wrong selection made \\
\hline
\end{tabular}

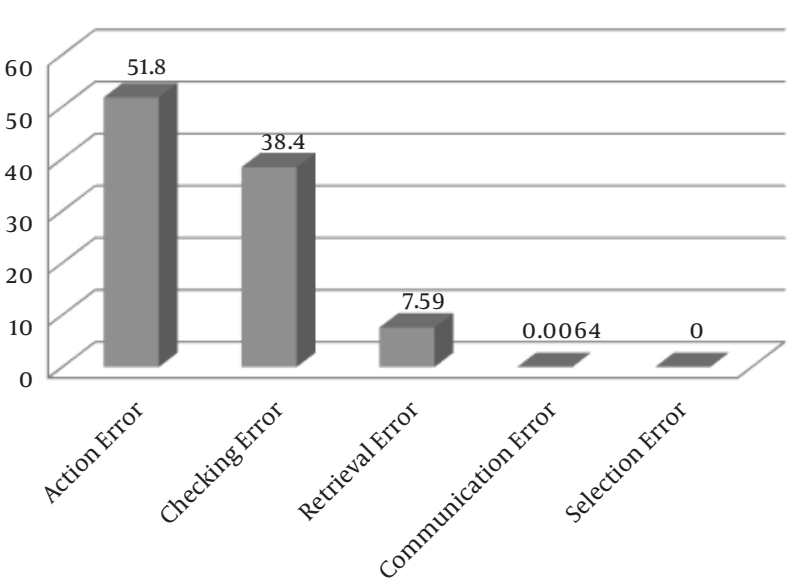

Figure 2. Types of Errors Identified

rors are identified because the operator tasks in the control room are operational, thus, it is natural that most of the errors to be of this type. The results of current study are similar to results from studies such as, Karimi (2015) (26), Dastaran et al. (2013) (27), Nezamodini et al. (2012) (28), Jafari et al. (2013) (29), Habibi et al. (2013) (30), and Mohammadfam and Saeidi (2014) (31). However, current results are different from the Mahdavi et al. study (2012) (32); where the most recognized errors in this study were retrieval errors. With regard to risk levels, a series of strategies to mitigate risk are presented, among them, the most error-reduction strategy is training. Lack of education and knowledge in operators are respectively $34 \%$ and $41 \%$ the causes of industrial accidents (33). In studies such as Adl et al. (2006, 2007), Qasemi et al. (2011), and Mohammadfam et al. (2002), deficiencies in education is determined as the main reason for the occurrence of human errors, therefore, the training courses have been proposed (34, 35). Also designing warning systems for reducing the risk level is the second proposed item with the most frequency among other proposals. In the current study, alarms play an important role in informing the operators of their status and working conditions unit. For example, deviations from normal conditions and any malfunction of equipment performance that can be due to operator error, is announced by an alarm. The alarm is any visible or audible warning device system, which shows abnormal conditions requiring corrective action. This study demonstrates that SHERPA is a comprehensive error prediction and prevention tool for identification of human error in complex sociotechnical systems such as water treatment plants. The results of the Hasanzadeh study in 2012, also recognizes that the human errors of cognitive failure occurs in 1 or all 3 stages of information processing (36), which is similar to our study. Therefore with application of integrated human error identification techniques, we can assume many different errors and defects such as external, internal and psychological errors. Application of an integrated method is suggested for development of safer operational procedures and therefore, this method can be used in order to predict human error rates on critical job tasks in the manufacturing industries (37).

\subsection{Conclusions}

Determination of human errors plays a key role in the prevention of errors; this benefit is followed by reducing the costs. Events due to human error in the supply and distribution of drinking water systems can contain menaces to public health and large-scale demolition of property, this part should be playing more of an active role in grasping and managing human risks, therefore, the results of this study can be the basis of planning for a critical job, to prioritize prevention programs and safety enhancement. SHERPA method has been selected for systemic examination of human errors in the telemetry control room. This method can identify and analyze human errors in very critical job tasks that the occurrence of human errors in them can lead to unpleasant consequences. It also provides control solutions for preventing errors. Although the 
Table 2. Sample Results of SHERPA in Lorestan Water Treatment Plant

\begin{tabular}{|c|c|c|c|c|c|c|c|}
\hline \multirow[b]{2}{*}{ Task Step } & \multicolumn{7}{|c|}{ Sherpa Work sheet } \\
\hline & Task Type & Error Mode & Description & Consequence & Recovery & Risk Level & Remedial Measure \\
\hline $0-2$ & Warning signs control & $\mathrm{A} 8 / \mathrm{C} 5$ & $\begin{array}{l}\text { Warning signs that } \\
\text { sent to the control } \\
\text { room to be forgotten or } \\
\text { be postponed to a later } \\
\text { time. }\end{array}$ & $\begin{array}{c}\text { Ignoring to signs } \\
\text { warning alarms led to } \\
\text { activate the Trip of the } \\
\text { unit. }\end{array}$ & & $2 \mathrm{D}$ & $\begin{array}{l}\text { Creating short } \\
\text { messages system- } \\
\text { Isolation emergency } \\
\text { alarms from less } \\
\text { important alarms. }\end{array}$ \\
\hline $0-2-1$ & $\begin{array}{l}\text { Timely action against } \\
\text { visible warning signs }\end{array}$ & $\mathrm{A} 1 / \mathrm{A} 9$ & $\begin{array}{c}\text { Timely action is done } \\
\text { later. }\end{array}$ & $\begin{array}{l}\text { Cause damage to } \\
\text { equipment or disrupt } \\
\text { water supply }\end{array}$ & & $2 \mathrm{~B}$ & $\begin{array}{l}\text { Preparation of audio } \\
\text { alarms. - Monitoring of } \\
\text { supervision. - develop } \\
\text { of instructions }\end{array}$ \\
\hline
\end{tabular}

Table 3. Risk Assessment Matrix

\begin{tabular}{|c|c|c|c|c|}
\hline Hazard Category Assessment Matrix & (1) Catastrophic & (2) Critical & (3) Marginal & (4) Negligible \\
\hline (A) Frequent & $1 \mathrm{~A}$ & $2 \mathrm{~A}$ & $3 \mathrm{~A}$ & $4 \mathrm{~A}$ \\
\hline (B) Probable & 1B & $2 \mathrm{~B}$ & 3B & $4 \mathrm{~B}$ \\
\hline (C) Occasional & $1 \mathrm{C}$ & $2 \mathrm{C}$ & $3 \mathrm{C}$ & $4 \mathrm{C}$ \\
\hline (D) Remote & $1 \mathrm{D}$ & $2 \mathrm{D}$ & $3 \mathrm{D}$ & $4 \mathrm{D}$ \\
\hline (E) Improbable & $1 \mathrm{E}$ & $2 \mathrm{E}$ & $3 \mathrm{E}$ & $4 \mathrm{E}$ \\
\hline
\end{tabular}

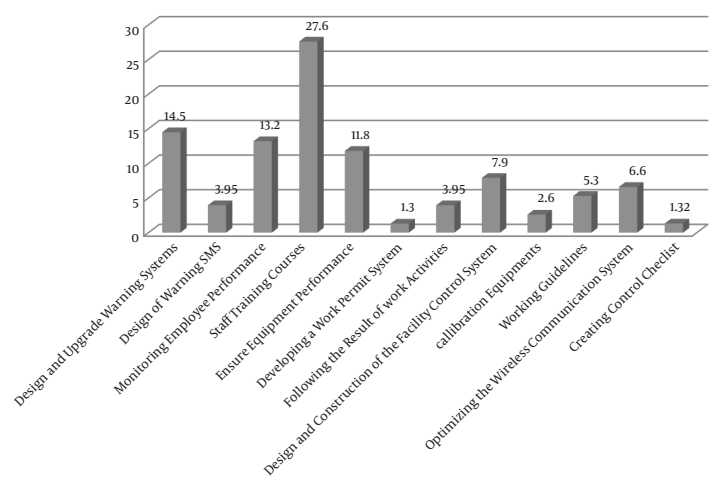

Figure 3. Proposals

issues and problems that lead to human errors often seem unavoidable, however, there are many ways to prevent and reduce errors or limit their consequences. Methods such as designing and upgrading warning systems, design of warning SMS, monitoring employee performance, staff training courses, developing a work permit system, following the result of work activities, design and construction of the facility control system, changing in high priority alarm sound, working guidelines, optimizing the wireless communication system, creating optimum ergonomic conditions in the workplace, and conducting periodic audits, can prevent or reduce the frequency of errors.

\section{Acknowledgments}

The authors appreciate the Lorestan water supply management for their interest and enthusiasm to cooperation in the study.

\section{References}

1. Horberry T, Burgess-Limerick R, Steiner LJ. Human factors for the design, operation, and maintenance of mining equipment. CRC Press; 2016. 
Table 4. Total Number of Identified Errors

\begin{tabular}{|c|c|c|c|}
\hline Error Category & Error Code & Error Mode & Number of Error (\%) \\
\hline \multirow{10}{*}{ Action Error } & A1 & Operation too long/short & $12(15.1)$ \\
\hline & $\mathrm{A} 2$ & Operation mistimed & $4(5.06)$ \\
\hline & A3 & $\begin{array}{l}\text { Operation in wrong } \\
\text { direction }\end{array}$ & $7(8.86)$ \\
\hline & A4 & Too little/much operation & $4(5.06)$ \\
\hline & A5 & Misalignment & $\mathrm{o}(0)$ \\
\hline & A6 & $\begin{array}{l}\text { Right operation on wrong } \\
\text { object }\end{array}$ & $0(0)$ \\
\hline & A7 & $\begin{array}{l}\text { Wrong operation on right } \\
\text { object }\end{array}$ & $0(0)$ \\
\hline & A8 & Operation omitted & $4(5.06)$ \\
\hline & A9 & Operation incomplete & $10(12.66)$ \\
\hline & A10 & $\begin{array}{l}\text { Wrong operation on wrong } \\
\text { object }\end{array}$ & $0(0)$ \\
\hline \multirow{6}{*}{ Checking error } & $\mathrm{C} 1$ & Check omitted & $14(17.79)$ \\
\hline & $\mathrm{C} 2$ & Check incomplete & $6(7.6)$ \\
\hline & $\mathrm{C}_{3}$ & Right check on wrong object & $4(5.06)$ \\
\hline & $\mathrm{C} 4$ & Wrong check on right object & $4(5.06)$ \\
\hline & C5 & Check mistimed & $2(2.53)$ \\
\hline & C6 & $\begin{array}{l}\text { Wrong check on wrong } \\
\text { object }\end{array}$ & $0(0)$ \\
\hline \multirow{3}{*}{ Retrieval error } & $\mathrm{R} 1$ & Information not obtained & $2(2.53)$ \\
\hline & $\mathrm{R} 2$ & $\begin{array}{l}\text { Wrong information } \\
\text { obtained }\end{array}$ & $2(2.53)$ \\
\hline & R3 & $\begin{array}{l}\text { Information retrieval } \\
\text { incomplete }\end{array}$ & $2(2.53)$ \\
\hline \multirow{3}{*}{ Communication error } & I1 & $\begin{array}{l}\text { Information not } \\
\text { communicated }\end{array}$ & $0(0)$ \\
\hline & I2 & $\begin{array}{l}\text { Wrong information } \\
\text { communicated }\end{array}$ & $1(0.0032)$ \\
\hline & 13 & $\begin{array}{c}\text { Information } \\
\text { communication incomplete }\end{array}$ & $1(0.0032)$ \\
\hline \multirow{2}{*}{ Selection error } & $\mathrm{S}_{1}$ & Selection omitted & $0(0)$ \\
\hline & S2 & Wrong selection made & $\mathrm{o}(0)$ \\
\hline $\begin{array}{l}\text { Total number of identified } \\
\text { errors }\end{array}$ & 79 & & \\
\hline
\end{tabular}

Table 5. Risk Level of Errors ${ }^{\mathrm{a}}$

\begin{tabular}{lcc}
\hline Risk Situation & Pre-Reform Risk Level & $\begin{array}{c}\text { After-Reform Risk } \\
\text { Level }\end{array}$ \\
\hline Unacceptable & $4(10.5)$ & $0(0)$ \\
\hline Undesirable & $28(73.6)$ & $4(10.5)$ \\
\hline $\begin{array}{l}\text { Acceptable, with } \\
\text { reviews }\end{array}$ & $4(10.5)$ & $21(55.2)$ \\
$\begin{array}{l}\text { Acceptable, without } \\
\text { reviews }\end{array}$ & $2(5.3)$ & $13(34)$ \\
\hline
\end{tabular}

${ }^{\mathrm{a}}$ Values are expressed as No. (\%).

2. Cloete S, Horberry T, Head B. Human factors in urban water system safety: Stage 1: Initial findings. Urban Water Security Research Alliance; 2011

3. Wu S, Hrudey S, French S, Bedford T, Soane E, Pollard S. A role for human reliability analysis (HRA) in preventing drinking water incidents and securing safe drinking water. Water Res. 2009;43(13):3227-38. doi: 10.1016/j.watres.2009.04.040. [PubMed: 19493557].
4. Hrudey SE, Hrudey EJ. Safe Drinking Water: Lessons from Recent Outbreaks in Affluent Nations London. Environ Health. 2004;4(3):55.

5. De Felice F, Petrillo A, Carlomusto A, Ramondo A. Human Reliability Analysis: A review of the state of the art. Int J Res Manag Technol. 2012;2(1).

6. Reason J. The contribution of latent human failures to the breakdown of complex systems. Philos Trans $R$ Soc Lond B Biol Sci. 1990;327(1241):475-84. [PubMed: 1970893].

7. Kariuki SG, Löwe K. Integrating human factors into process hazard analysis. Reliabil Engin System Safety. 2007;92(12):1764-73. doi: 10.1016/j.ress.2007.01.002.

8. Ren J, Jenkinson I, Wang J, Xu DL, Yang JB. A methodology to model causal relationships on offshore safety assessment focusing on human and organizational factors. J Safety Res. 2008;39(1):87-100. doi: 10.1016/j.jsr.2007.09.009. [PubMed:18325420].

9. Helmreich RL. On error management: lessons from aviation. BMJ. 2000;320(7237):781-5. [PubMed: 10720367]

10. Hollnagel E. Human reliability analysis: Context and control. Academic press; 1993.

11. Reinach S, Viale A. Application of a human error framework to conduct train accident/incident investigations. Accid Anal Prev. 2006;38(2):396-406. doi: 10.1016/j.aap.2005.10.013. [PubMed: 16310153].

12. Stanton NA, Stevenage SV. Learning to predict human error: issues of acceptability, reliability and validity. Ergonomics. 1998;41(11):1737-56. doi: 10.1080/001401398186162. [PubMed: 9819584].

13. Baber C, Stanton NA. Human error identification techniques applied to public technology: predictions compared with observed use. Appl Ergon. 1996;27(2):119-31. [PubMed: 15677051].

14. Salmon PM, Stanton NA, Baber C, Walker GH, Green D. Human factors design and evaluation methods review. Human Factors Integrat Defence Technol Rep. 2004:1-586.

15. Stanton NA, Salmon P, Walker G. Human factors design methods review. ; 2003.

16. Lyons M. Towards a framework to select techniques for error prediction: supporting novice users in the healthcare sector. Appl Ergon. 2009;40(3):379-95. doi: 10.1016/j.apergo.2008.11.004. [PubMed: 19091307].

17. Lane R, Stanton NA, Harrison D. Applying hierarchical task analysis to medication administration errors. Appl Ergon. 2006;37(5):669-79. doi: 10.1016/j.apergo.2005.08.001. [PubMed: 16182230].

18. Embrey DE. Quantitative and qualitative prediction of human error in safety assessments. Hemsphere publishing corporation; 1993.

19. Stanton NA, Hedge A, Brookhuis K, Salas E, Hendrick HW. Handbook of human factors and ergonomics methods. CRC press; 2004.

20. Rothschild JM, Landrigan CP, Cronin JW, Kaushal R, Lockley SW, Burdick E, et al. The Critical Care Safety Study: The incidence and nature of adverse events and serious medical errors in intensive care. Crit Care Med. 2005;33(8):1694-700. [PubMed:16096443].

21. Stanton NA, Salmon P. Human factors design \& evaluation methods review. Defense Technology Center; 2004.

22. Embrey DE. Task analysis techniques. Human reliability associates Ltd; 2000.

23. Kirwan B. A guide to practical human reliability assessment. CRC press; 1994.

24. Embrey DE, editor. SHERPA: A systematic human error reduction and prediction approach. Proceedings of the international topical meeting on advances in human factors in nuclear power systems. 1986; .

25. Stanton NA, Salmon PM, Rafferty LA. Human factors methods: a practical guide for engineering and design. Ashgate Publishing, Ltd; 2013.

26. Karimi S. Identification and assessment of human errors in blasting operations in Iron Ore Mine using SHERA technique. J Occup Hygiene Engin. 2015;2(1):57-65.

27. Dastaran S, Hasheinejhad N, Shahravan A, Baneshi M, Faghihi A. Identification and Assessment of Human Errors in Postgraduate Endodon- 
tic Students of Kerman University of Medical Sciences by Using the SHERPA Method. J Occup Hygiene Engin. 2016;2(4):44-51.

28. Nezamodini ZA, Orosi M, Mombeni B. Assessment of human errors in paper machines of pars paper industrial group by Predictive Human Error Analysis (PHEA). Jundishapur J Health Sci. 2013;4(4):17-24.

29. Jafari MJ, Haji Hoseini AR, Halvani GH, Mehrabi Y, Ghasemi M. Prediction and Analysis of Human Errors in Operators of Control Rooms at $400 \mathrm{kV}$ Posts and the Effectiveness of the Proposed Measures. Iran Occup Health. 2012;9(3):60-71.

30. Habibi E, Gharib S, Mohammadfam I, Rismanchian M. Human error assessment in Isfahan oil refinery's work station operators using systematic human error reduction prediction approach technique. Int $J$ Environ Health Engin. 2013;2(1):25. doi:10.4103/2277-9183.113214.

31. Mohammadfam I, Saeidi C. Evaluating human errors in cataract surgery using the SHERPA technique. J Ergon. 2015;2(4):41-7.

32. Mahdavi S, Farsani EH, Taajvar A. Identification and assessment of human error due to design in petroleum refinery sour water equipment damage by SHERPA.J Health SafWork. 2013;2(4):61-70.
33. Shorrock ST, Kirwan B. Development and application of a human error identification tool for air traffic control. Appl Ergon. 2002;33(4):319-36. [PubMed: 12160336].

34. Adl J, Mohammadfam I, Nezam A. Evaluation of chorine leakage hazards in chlorination stations of Tehran water purification system by FTA technique.; 2008 .

35. Nezamodini ZS, Khodamoradi F, Malekzadeh M, Vaziri H. Nursing Errors in Intensive Care Unit by Human Error Identification in Systems Tool: A Case Study.Jundishapur J Health Sci. 2016;8(3) doi: 10.17795/jjhs36055.

36. Hassanzadeh Rangi N, Allahyari T, Khosravi Y,Zaeri F, Saremi M. Development of an Occupational Cognitive Failure Questionnaire (OCFQ): Evaluation validity and reliability. Iran Occup Health. 2012;9(1):29-40.

37. Cheng CM, Hwang SL. Applications of integrated human error identification techniques on the chemical cylinder change task. Appl Ergon. 2015;47:274-84. doi: 10.1016/j.apergo.2014.10.008. [PubMed: 25479998]. 